\title{
Während der Schulferien stecken häufiger Pneumokokken dahinter
}

\author{
Bei Lungenentzündungen Erwachsener werden während der Schulferien deutlich \\ häufiger als in Schulzeiten Pneumokokken als Erreger identifiziert.
}

_ Kontakt mit Kindern ist für Erwachsene ein Risikofaktor für Pneumokokken-Infektionen. Dies zeigt auf eindrückliche Weise die Untersuchung eines Autorenteams der Universität Nottingham. Es hatte zwischen 2008 und 2013 in zwei Krankenhäusern das Erregerspektrum von 2.221 Patienten mit ambulant erworbenen Pneumonien unter die Lupe genommen und nach Unterschieden im Erregerspektrum in den Zeiten der Schulferien gefahndet.
In 643 Fällen (29\%) lag eine Pneumokokken-Pneumonie vor. 203 dieser Pneumonien traten während der Schulferien auf. Das ist überzufällig häufig angesichts der Kürze der Schulferien. Tatsächlich war die Wahrscheinlichkeit eines Pneumokokken-Nachweises in den Schulferien nach Adjustierung für andere Variable um 35\% höher als in Schulzeiten, berichtete Studienautorin Priya Daniel. Personen mit Risikofaktoren für Pneumokokken-Infektionen wie etwa die Großeltern können sich ganz einfach schützen, indem sie die empfohlene Pneumokokken-Schutzimpfung durchführen lassen.

Dr. Dirk Einecke

- International Congress 2016 der European Respiratory Society ERS, London, 3.-7. September 2016

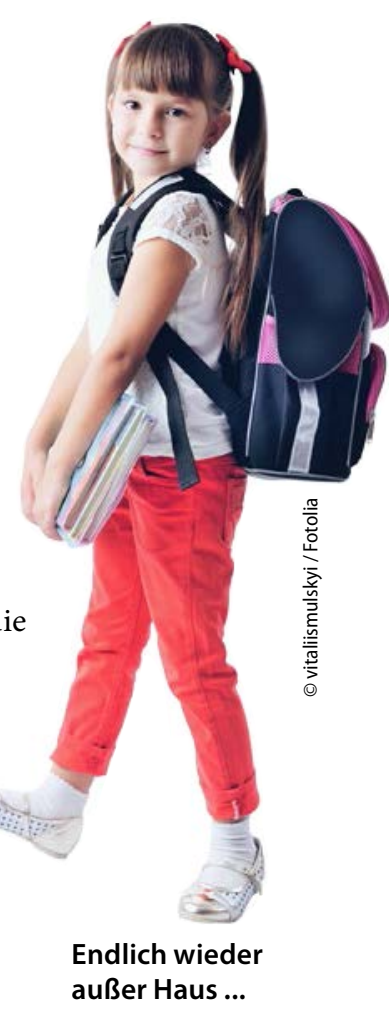

\section{Hier steht eine Anzeige.}

照 Springer 